Apidologie, 1985, 16 (4), 343-368

\title{
UNTERSUCHUNGEN ZUR QUANTITATIVEN ABSCHÄTZUNG DES BEFALLS VON BIENENVÖLKERN MIT VARROA JACOBSONI OUDEMANS UND ZUR VERTEILUNG DES PARASITEN IM BIENENVOLK
}

\author{
S. FUCHS
}

Institut für Bienenkunde (Polytechn. Gesellschaft), J.W. Goethe Universität Frankfurt/Main Fachbereich Biologie, Karl-von-Frisch-Weg 2, D 6370 Oberursel/Ts, F.R.G.

Mit Unterstützung der Europäischen Gemeinschaft durch das Sofortprogramm Varroatose

\section{ZUSAMMENFASSUNG}

Die Zuverlässigkeit von Verfahren zur Schätzung der Anzahl von Varroamilben in Bienenvölkern aus Bienenproben oder Brutproben wurde untersucht. Eine Korrelation zwischen dem Probenbefall und dem Befall der Völker konnte bestätigt werden. Allerdings waren bei beiden Verfahren die Streuungen sowohl zwischen Proben aus einem Volk als auch zwischen den Völkern so hoch, daß mit häufigen gravierenden Fehldiagnosen zu rechnen ist. Brutproben erwiesen sich als weniger zuverlässig als Bienenproben. Die Verteilung der Milben zwischen Brut und Bienen sowie auf den Brutwaben deutet darauf hin, daß unbekannte Faktoren einen unregelmäßigen Übergang der Milben in die Brutzellen verursachen.

\section{EINLEITUNG}

Bei den bisherigen Verfahren zur Diagnose von Varroa jacobsoni in Völkern der Honigbiene $A$. mellifica lag der Schwerpunkt zunächst vorwiegend auf einer möglichst frühzeitigen und sicheren Erkennung eines Befalls. Mit zunehmender allgemeiner Verbreitung des Parasiten gewinnt demgegenüber die Frage nach der Bestimmung der Befallsstärke immer mehr an Bedeutung. Ein solches Verfahren könnte es ermöglichen, schwach befallene Völker unbehandelt zu lassen und damit - zumal nach Entwicklung effektiver Behandlungsmethoden - mit einem durchschnittlich 2-jährigen Bekämpfungszeitraum auszukommen. Weiter ist bei der Überschreitung einer Befallsstärke von nach unseren Beobachtungen ca. 5000 Varroa pro Bienenvolk im Sommer mit Volkszusammenbrüchen zu rechnen. Dies ist unbedingt zu vermeiden, da der Verflug der Restbienen und das Aus- 
räubern der geschwächten Völker wesentlich zur Verbreitung der Milben auf die umliegenden Völker beitragen dürfte. Auch hieraus ergibt sich die Notwendigkeit einer einigermaßen zuverlässigen Abschätzung der Befallsstärke. Weiter ist bei Anwendung und Entwicklung neuer Behandlungsmethoden, besonders bei biologischen Kontrollmaßnahmen wie dem Bannwabenverfahren oder der Drohnenbrutentnahme eine Methode zur Kontrolle des Behandlungserfolgs erforderlich.

Um in der Praxis Befallsbestimmungen durchführen zu können, müssen diese von der Methode her einfach sein. Die Untersuchung von Bienenproben oder Brutproben ist ein cingeführtes Verfahren (RITTER und RuTTNER, 1980 ; MAUL et al., 1984). Gegenüber Flugbienen weisen Stockbienen einen höheren Befall auf (HütTINGER et al., 1980, KRAUS, 1985) und sind daher zur Diagnose besser geeignet. Bei der Untersuchung von Brutproben wurde ausschießlich Arbeiterinnenbrut in Betracht gezogen. Die Untersuchung der Drohnenbrut ist wegen des hohen Befallsgrades eine eingeführte Standardmethode zur Feststellung eines Varroabefalls, ist aber wegen der sehr unregelmäßigen Drohnenbrutmengen und der damit verbundenen Schwankungen des Befallsgrades für die quantitative Diagnostik weniger geeignet. Eine zusätzliche Einschränkung bildet der begrenzte Zeitraum der Drohnenbruterzeugung.

Eine positive Korrelation der aus Proben ermittelten Bienen- und Brutbefallswerte mit dem Gesamtbefall wurde bereits von FrEmuTh (1984) sichergestellt. Die vorliegende Untersuchung legt ihren Schwerpunkt auf die Beurteilung der Zuverlässigkeit des Rückschlusses aus den Proben auf den Befall. In engem Zusammenhang hiermit steht die Frage nach der Verteilung von Varroa im Bienenvolk, da diese unmittelbar die bei den Probennahmen erhaltenen Befallszahlen beeinflussen kann. Angaben hierzu können auch im Hinblick auf eine weitere Aufklärung der Biologie von Varroa von Nutzen sein.

\section{MATERIAI UND METHODEN}

\section{Befallsdiagnose (Serie 1-4)}

\section{a) Probenmaterial}

Die analysierten Untersuchungsdaten (Serie 1-4) waren vom Standort der Völker, Auswertungsverfahren und Auswertungszeitpunkt her verschieden. Dies entspricht der Intention, möglichst generalisierbare Ergebnisse zu erhalten. Tabelle 1 zeigt Anzahl der untersuchten Völker sowie Anzahl und Umfang der entnommenen Proben.

Serie 1 : Bei 11 sehr stark von Varroa befallenen Völkern nahe dem Volkszusammenbruch (6 Völker bei Hochheim, 15.7. ; 5 Völker bei Worms, 23.7.) wurden die Bienen wabenweise abgekehtt und die Brutwaben entnommen. Die Völker entstammten Magazinbeuten mit 2 Zargen, sie enthielten in der Regel 20 Waben, in einigen Fällen etwas weniger. Die Reihenfolge der Waben wurde notiert. Die Bienen von jeder einzelnen Wabe ergaben jeweils eine Bienenprobe. Die 
Anzahl der Bienen in den insgesamt 210 Bienenproben war je nach Besetzung der Waben sehr unterschiedlich. Die verdeckelten Bereiche der Brutwaben wurden je nach Größe in bis zu 5 Biutproben zerschnitten.

TAB. 1. - Untersuchungserien (1-4) und Probenumfänge

TABL. 1. - Sample series (1-4) and sample sizes

\begin{tabular}{|c|c|c|c|c|c|}
\hline & \multirow{2}{*}{$\begin{array}{c}\text { Völker } \\
\text { Bee hives } \\
\text { N }\end{array}$} & \multicolumn{2}{|c|}{$\begin{array}{c}\text { Bienenproben } \\
\text { Bee samples }\end{array}$} & \multicolumn{2}{|c|}{$\begin{array}{l}\text { Brutproben } \\
\text { Brood cell samples }\end{array}$} \\
\hline & & $\mathrm{n}$ & $\mathrm{B} / \mathrm{n}$ & $\mathrm{n}$ & $\mathrm{Z} / \mathrm{n}$ \\
\hline $\begin{array}{ll}\text { Serie } 1 \\
\text { Series } 1\end{array}$ & 11 & 210 & $965 \pm 706$ & 210 & $318 \pm 175$ \\
\hline $\begin{array}{ll}\text { Serie } 2 \\
\text { Series } 2\end{array}$ & 16 & 205 & $1040 \pm 630$ & 70 & $1101 \pm 949$ \\
\hline $\begin{array}{ll}\text { Serie } 3 \\
\text { Series } 3\end{array}$ & 19 & - & - & 192 & $394 \pm 203$ \\
\hline $\begin{array}{ll}\text { Serie } 4 \\
\text { Series } 4\end{array}$ & 49 & $4 !$ & $429 \pm 78$ & - & - \\
\hline
\end{tabular}

Anzahl der Völker (N), Anzahl der entnommenen Proben (n) und Umfang der Proben (Bienen/Proben, B/n ; Zellen/Proben, Z/n).

Number of hives $(N)$, number of samples (n) and sample sizes (bees $/$ sample, $B / n$; brood cells/sample, $\mathrm{Z} / \mathrm{n}$ ).

Serie 2 : Bei einer Untersuchung von 16 Völkern in Hohenheim (Fremuth, 1983) wurden jeweils 4 der unterschiedlich stark befallenen Völker am 1.8., 29.8., 28.9. und 24.10. abgetötet und entsprechend den oben angegebenen Methoden nach im wesentlichen gleichen Gesichtspunkten ausgewertet. Die verdeckelten Brutbereiche der einzelnen Waben wurden nicht weiter unterteilt. Die Völker befanden sich in Magazinbeuten mit einer Zarge (11), 2 Zargen (4) oder 3 Zargen (1); jede Zarge enthielt 10 Waben.

Serie 3 : 19 Völker aus Oberursel wurden am 26.4. abgetötet. Die Auswertung der Brutwaben erfolgte wie in Serie 1. Die Anzahl von Varroa auf Bienen wurde nur insgesamt bestimmt, sodaß in dieser Serie keine Bienenproben zur Verfügung standen. Die Völker befanden sich in Magazinen mit 2 Zargen.

Serie 4 : Aus 49 brutlosen Bienenvölkern wurden im Herbst (1.10.) je eine Bienenprobe entnommen und ausgewaschen. Die in drei nachfolgenden Behandlungen mit Folbex VA Neu abgefallenen Milben dienten als Schätzungen des Gesamtbefalls des Volkes. Die Nachuntersuchung von 18 der Völker mit K 79 ergab einen Restmilbenbestand von im Durchschnitt 4,5\%.

\section{b) Auswertung der Proben}

Bei den Bienenproben wurde die Anzahl der Bienen durch Auswiegen geschätzt (Bienenzahl $=10 \times$ Bienengewicht in g). Zur Bestimmung der Anzahlen der Varroamilben wurden 
die Proben in detergentienhaltigem Wasser ausgewaschen (RITTER, 1980; DE Jong et al., 1982). Hierzu bewährten sich Gefäße mit Siebeinsatz (Abb. 1), die $30 \mathrm{~min}$ in einen Rüttler eingestellt wurden. In nachfolgenden Probeauswaschungen wurden nur noch geringe Anzahlen von Milben gefunden (55 Proben, 1. Auswaschung 1936 Varroae, 2. Auswaschung 15 Varroae 0.77\%). Dies deutet darauf hin, daß die Methode eine Genauigkeit von etwa $99 \%$ erreicht und damit mit der Auswaschung in Benzin vergleichbar ist (RITTER und RutTNER, 1980).

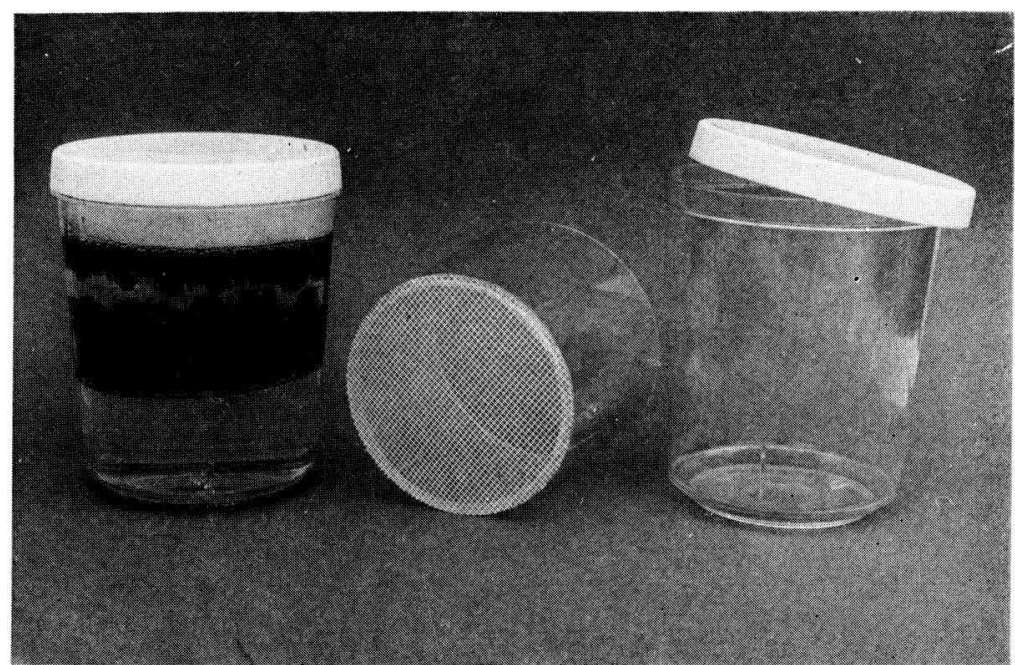

Aвв. 1. - Schüttelbecher zur Trennung von Bienen und Varroamilben

Von rechts : Honigbehälter aus Plastik, Einsatz mit aufgeklebtem Gazesieb, Deckel, montierter Schüttelbehälter mit ca. 0,5\%-iger Detergenzienlösung und Bienenprobe.

FIG. 1. - Shaking container to separate bees and varroa mites

From right to left : Plastic honey container, insert with glued-on gauze sieve, lid, mounted container with bee sample and approx. $0.5 \%$ detergent water.

Bei den Brutproben wurde die Anzahl der Zellen durch Ausmessen der Brutflächen geschätzt (4 Zellen $/ \mathrm{cm}^{2}$ ). Der Varroabefall wurde durch Auswaschen der Brutproben mit einer Spültischbrause ermittelt (RITTER et al., 1983, MaUL, 1984). Hierbei erhält man nur die adulten Varroae, die Larvenstadien gehen verloren.

\section{Verteilung von Varroa im Volk (Serie 5-7)}

Serie 5 : Aus 20 Völkern wurden bei beginnender Wintertraubenbildung im Herbst (25.11.) je 2 Bienenproben mit im Durchschnitt $420 \pm 78$ Bienen entnommen und ausgewaschen. Eine dieser Proben entstammte dem Mittelbereich, eine dem Randbereich der Völker.

Serie 6 : 65 Wabenstücke mit im Mittel ca. 100 Zellen (96士39, 34 Proben Arbeiterinnenbrut, 31 Proben Drohnenbrut) wurden zellenweise geöffnet und die Anzahl eingedrungener Varroae bestimmt. Die Auswertungen waren von Dr. A. Schulz vorgenommen und die Ergebnisse zur Verfügung gestellt worden. 
Serie 7 : Zur Bestimmung der Verteilung von Varroa auf Brutwaben wurden die verdeckelten Bereiche von drei Brutwaben zellenweise geöffnet und die Anzahl enthaltener Varroa und das Entwicklungsstadium der Bienenbrut (Larve, Puppe mit weißen Augen, Puppe mit dunklen Augen) bestimmt. Die Ergebnisse wurden entsprechend der Position der Zellen auf Sechseckvordrucken eingetragen.

\section{ERGEBNISSE}

I. Abschätzung des Gesamtbefalls aus dem relativen Befall von Bienenproben

\section{a) Berechnungsformel}

Der relative Bienenbefall $(\mathrm{rBi}=$ Anzahl Varroa/Anzahl Bienen) in den Proben aus den Serien 2, 3, 4 korreliert deutlich mit der Gesamtzahl (gV) von Varroa im ganzen Bienenvolk ( $r=0,62 ; p<0,001)$. Der Zusammenhang wird durch die lineare Regression $\mathrm{rBi}=1,2510^{-\overline{5}} \mathrm{gV}+0,057$ beschrieben. Der niedrige Korrelationskoeffizient weist auf die ausserordentlich hohen Streuungen hin.

Als geeignete Schätzformel für den Gesamtbefall aus dem rel. Probenbefall wurde eine Gerade durch den Nullpunkt entsprechend der Formel $\mathrm{GA}=\mathrm{Bif} \cdot \mathrm{rBi} \cdot \mathrm{z}$ angesehen $(\mathrm{GA}=$ geschätzte Gesamtvarroa, $\mathrm{rBi}=$ rel. Bienenprobenbefall). Die Einbeziehung der Anzahl von Zargen in den Magazinbeuten (z) ermöglicht eine ungefähre Berücksichtigung der Volksstärke. Als Umrechnungsfaktor (Bif) diente der Wert, bei dem die Standardabweichung der mit der Umrechnungsformel erhaltenen Schätzwerte von den tatsächlichen Befallswerten am kleinsten wurde. Diese betrug bei einem Faktor von Bif $=22500$ für die logarithmisch transformierten Werte $\pm 0,29$ und war damit deutlich geringer als bei Verwendung der Regression von $\mathrm{gV}$ auf $\mathrm{rBi}$ als Umrechnungsgrundlage $( \pm 0,42)$.

\section{b) Schätzgenauigkeit}

Die nach der Schätzformel erhaltenen Schätzwerte für den Gesamtbefall sind in Fig. 2 (Ordinate) gegen die tatsächlichen Befallswerte (Abszisse) unter Verwendung eines logarithmischen Maßstabs aufgetragen. Für die Schätzwerte aus Serie 1 und Serie 2 wurden Mittelwerte und die $95 \%$ Vertrauensbereiche angegeben. Diese geben eine Spanne von ungefähr doppelter Standardabweichung an, aus der im Durchschnitt jeder zwanzigste Schätzwert herausfällt. Für die logarithmisch transformierten Werte umfasst der Vertrauensbereich innerhalb der Völker im Durchschnitt $\pm 0,32$, also eine Gesamtspanne von 2/3 Zehnerpotenz. Im linearen System entspricht dies einem Vertrauensbereich mit einer unteren Grenze von Mittelwert / 2,1 und einer oberen von Mittelwert 2,1. Bereits die aus verschiedenen Bienenproben des gleichen Volks gewonnenen Schätzwerte schwanken damit über einen sehr weiten Bereich. 


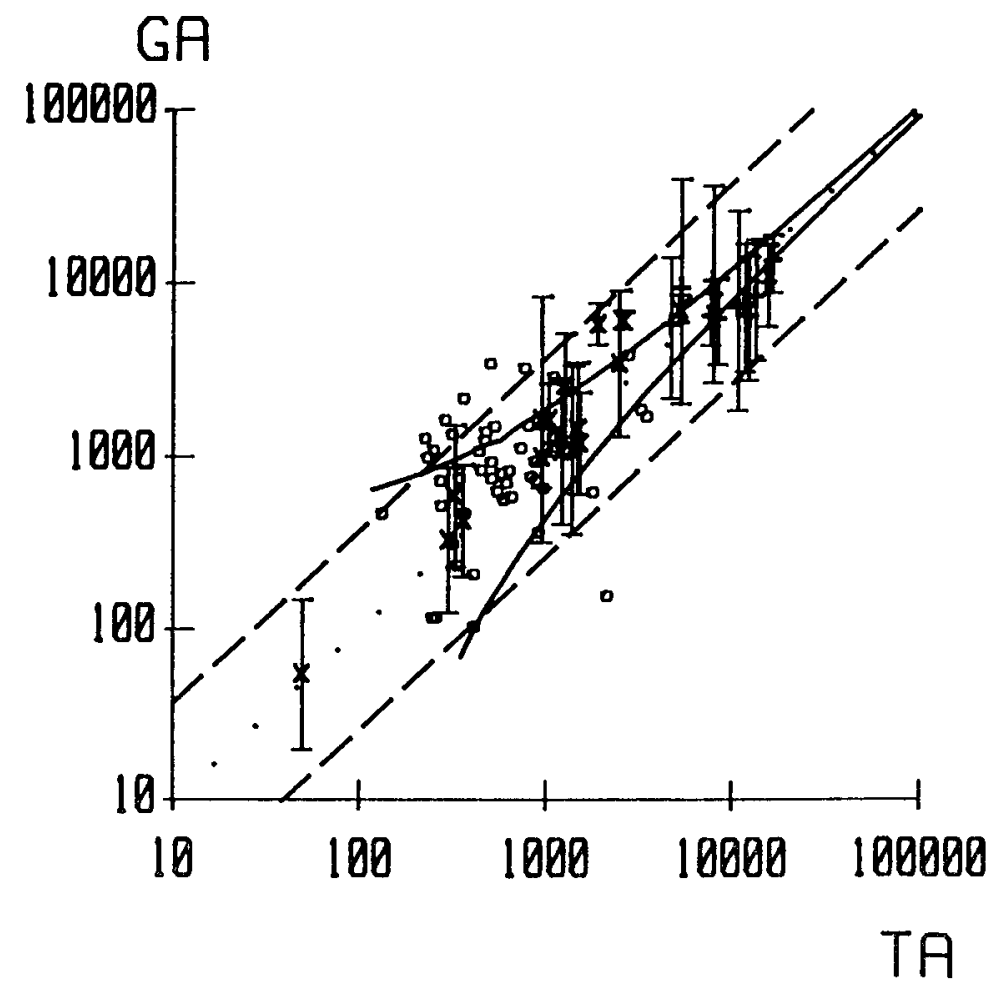

Aвв. 2. - Schützung des Gesamtbefalls der Völker aus Bienenproben

Serie $1(+)$ und $2(x)$ : Mittelwerte und 95\% Vetrauensbereiche (ca. 20 Proben/Volk); Serie 3 (o) : 1 Probe/Volk. Abszisse : tatsächliche Milbenanzahl (TA), Ordinate : geschätzte Milbenanzahl (GA). Gestrichelte Linien : $95 \%$ Vertrauensbereich aller Einzelschätzwerte. Durchgezogene Linien : $95 \%$ Vertrauensbereich bei zufälliger Streuung des Probenbefalls (Probenumfang 350 Bienen).

\section{FIG. 2. - Estimates from bee samples of the infestation of bee hives}

Series $1(+)$ and series $2(x)$ : means and $95 \%$ confidence intervals (approx. 20 samples/hive), series $3(0)$ : one sample/hive. Abscissa : actual number of mites (TA). Ordinate : estimated number of mites (GA). Broken lines : $95 \%$ confidence interval of all samples combined. Solid lines : $95 \%$ confidence interval with chance deviations of sample infestation (sample size $=350$ ).

Hinzu kommen die Abweichungen der Mittelwerte selbst, die überwiegend Unterschiede zwischen den Völkern reflektieren. Bei Werten auf der Diagonalen (gepunktet) stimmen Schätzwert und tatsächlicher Wert überein. Das Diagramm zeigt deutlich, daß die ermittelte Schätzformel den Zusammenhang zwischen rel. Probenbefall und tatsächlichem Befall im Prinzip angemessen erfasst und daß die Mittelwerte ohne erkennbare Regelmäßigkeit abweichen. Für diese ergibt sich ein $95 \%$-iger Vetrauensbereich um den tatsächlichen Wert mit einer Breite von \pm 0.44 für die logarithmischen Werte. Unterschiede zwischen den Völkern tragen 
damit noch stärker zur Ungenauigkeit der Schätzung bei als Unterschiede zwischen den Proben aus einem Volk.

Die Werte aus Serie 3 repräsentieren immer nur eine Probe aus einem Volk und ordnen sich in ihrer aus beiden Effekten - Unterschieden zwischen den Völkern und Unterschieden zwischen Proben aus einem Volk - zusammengesetzten Streuung in das Gesamtbild der anderen beiden Serien ein.

Aus allen Einzelwerten lässt sich damit der $95 \%$-ige Vetrauensbereich für die Abweichung der Schätzwerte von den tatsächlichen Werten ermitteln. Die Breite dieses Streifens beträgt $\pm 0,58$ und ist in Fig. 2 durch gestrichelte Linien angegeben. Seine Gesamtbreite übersteigt damit eine Zehnerpotenz. Im linearen System entspricht dies einer unteren Grenze von tatsächlichem Befall / 3,8 und einer oberen Grenze von tatsächlichem Befall 3,8.

Die Anordnung der Werte in diesem Streifen lässt erkennen, daß deren Variabilität durch einen solchen konstanten Faktor angemessen repräsentiert wird. Man verschätzt sich demnach bei hohem Milbenbefall um absolut weit größere Milbenanzahlen als bei niedrigem. Dies ist nicht selbstverständlich. Geht man von rein statistischen Schwankungen der Varroazahlen in den Proben bei ansonsten völlig gleichmäßigen Verhältnissen aus, so ist mit steigendem Varroabefall mit relativ immer genaueren Schätzungen zu rechnen, da die absoluten Milbenzahlen in den Proben immer größer und damit von Zufallsschwankungen relativ weniger beeinflußt werden. Ausgehend von Proben mit 350 Bienen sollten dann bei Zugrundelegung einer Poissonverteilung $95 \%$ aller Schätzwerte in dem Bereich zwischen den durchgezogenen Linien in Fig. 2 zu liegen kommen. Die Überschreitung dieses sich verengenden Bereichs durch die tatsächlichen Schätzwerte bei den höheren Befallswerten zeigt deutlich, daß die Variabilität der Schätzwerte überwiegend auf nicht zufällige Unterschiede bei der Probennahme, also auf tatsächliche Unterschiede des rel. Bienenbefalls sowohl innerhalb der Völker als auch zwischen den Völkern zurückzuführen ist.

c) Verteilungsunterschiede von Varroa auf Bienen als Ursachen der Schätzungenauigkeit

1) Aus den vorliegenden Ergebnissen lassen sich wenig klare Hinweise auf die Art der Unterschiede zwischen Völkern oder Serien gewinnen, die zu den jeweiligen Über- oder Unterschätzungen beigetragen haben. Offensichtlich ist aber die Brutmenge von Bedeutung. Bei 26 Völkern der Serien 1 und 2 waren bei überdurchschnittlich vicl enthaltener Brut (im Mittel 5200 Zellen) die Mittelwerte der Schätzungen meist unter $(11: 2)$, bei unterdurchschnittlich viel Brut meist über dem tatsächlichen Befall $\left(9: 4 ; \mathrm{p}<0,01 ; \mathrm{Chi}^{2}\right.$-Test).

2) Es wurde überprüft, ob die Abweichungen zwischen den Hochrechnungsergebnissen aus verschiedenen Proben eines Volkes auf unterschiedliche Milben- 
dichten in verschiedenen Zonen der Völker beruhen. Hierzu wurden Mittelwerte aus dem rel. Bienenbefall aus den Proben mit gleicher Position im Bienenvolk gebildet. Um den unterschiedlichen Gesamtbefall der Völker auszugleichen, wurden die rel. Befallswerte der einzelnen Proben durch Division mit dem rel. Gesamtbefall der Bienen des ganzen Volks normalisiert. Fig. 3 zeigt den normalisierten mittleren rel. Bienenbefall der aufeinanderfolgenden Waben in den Zargen für Serie 1 und 2. In Serie 1 ist ein deutlich höherer Befall der 4 mittleren Waben (Nr. 4-7; Mittelwert $=1,23 \pm 0,34, \mathrm{~N}=47$ ) gegenüber den 6 randständigen Waben statistisch gut gesichert (Nr. 1-3 und 8-10; Mittelwert $=0,983 \pm 0,44$, $\mathrm{N}=69 ; \mathrm{t}=4,56$, df $=50, \mathrm{p}<0,0001)$. In Serie 2 mit einem im Schnitt wesentlich geringerem Gesamtbefall ist dies weit weniger ausgeprägt, aber immer noch signifikant (Mittelwaben : Mittelwert $=1,06 \pm 0,38, \mathrm{n}=87$; Randwaben : Mittelwert $=0,94 \pm 0,41, \mathrm{~N}=115 ; \mathrm{t}=2,93$, df $=90, \mathrm{p}<0,01$ ).
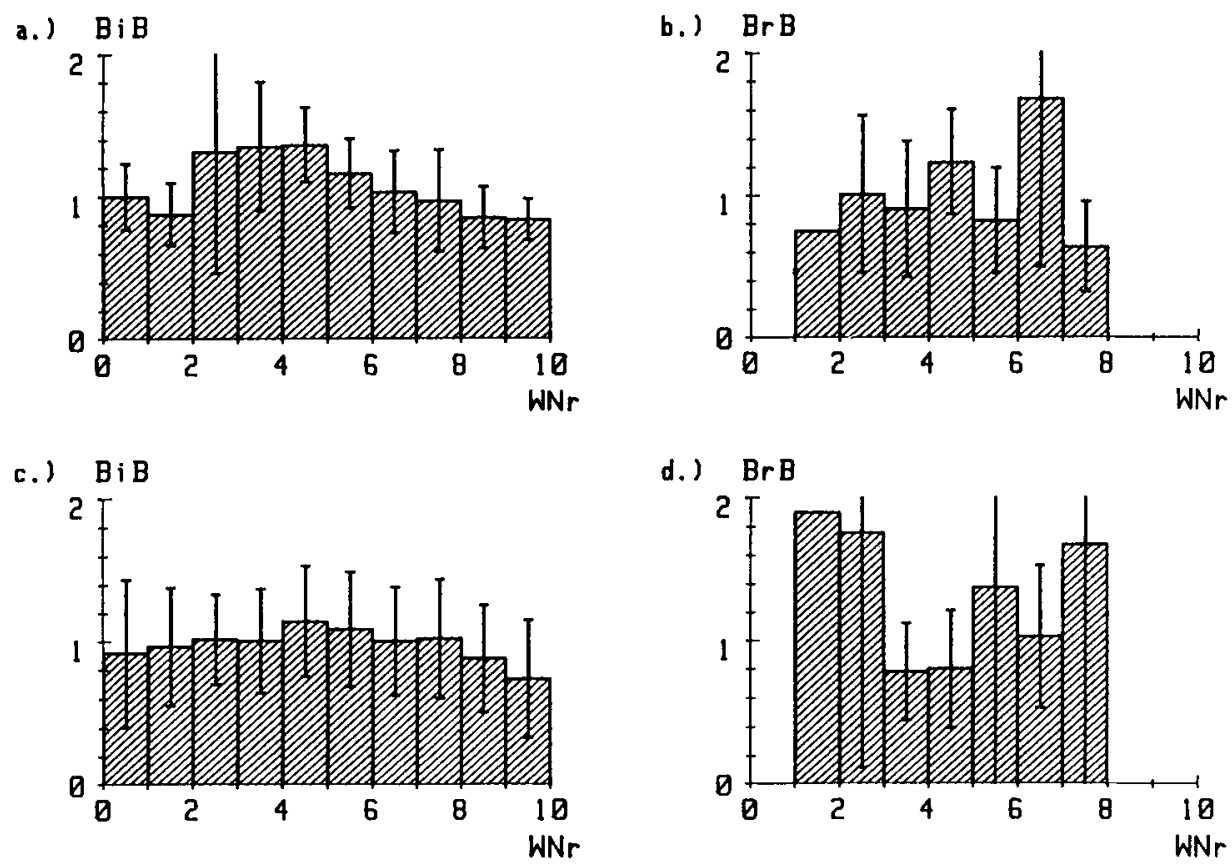

Aвв. 3, - Bienenbefall $(\mathrm{BiB})$ und Brutbefall $(\mathrm{Br} \mathrm{B})$ in Abhängigkeit von der Position der Waben in den Zargen (Mittelwerte und Standardabweichungent).

Abszisse : Wabennummer (WNr), Ordinate : Am Befall des Volks normierter rel. Befall. Serie 1 : a) Rel. Bienenbefall, b) rel. Brutbefall. Serie 2 : c) rel. Bienenbefall, d) rel. Brutbefall.

FIG. 3. - Infestation rate of bees (BiB) and worker brood cells (BrB) according to the position of the combs in the hive chambers (means and standard deviations).

Abscissa : number of comb frame (WNr). Ordinate : infestation normalized by the infestation of the hive; means and standard deviation. Series $1:$ a) rel. bee infestation, b) rel. brood cell infestation. Series $2:$ c) rel. bee infestation, d) rel. brood cell infestation. 
Der normalisierte rel. Bienenbefall war deutlich und signifikant höher auf Waben mit Brut (Mittelwert $=1,20 \pm 0,37, \mathrm{~N}=137$ ) im Vergleich zu brutfreien Waben (Mittelwert $=0,95 \pm 0,41, \mathrm{~N}=266 ; \mathrm{t}=6,42$, df $=147, \mathrm{p}<0,0001$ ). Die Brutmenge auf einer Wabe wirkt sich dagegen nur undeutlich aus. Die lineare Regression von der Brutmenge (wenige bis über 3000 ) auf den normierten rel. Bienenbefall zeigt nur einen sehr geringen Anstieg, die Korrelation ist nicht signifikant $\left(\mathrm{y}=5 \cdot 10^{-5} \cdot \mathrm{x}+1,15, \mathrm{r}=0,12, \mathrm{n}=137 \mathrm{~ns}\right)$. Im Bereich der Mittelwaben selbst (Nr. 3-7) haben Waben mit Brut einen höheren normalisierten rel. Bienenbefall (Mittelwert $=1,21 \pm 0,39, \mathrm{~N}=96$ ) als solche ohne Brut (Mittelwert $=1,00 \pm 0,38, \mathrm{~N}=82, \mathrm{t}=3,67, \mathrm{df}=91, \mathrm{p}<0,002$ ). Dies ist noch deutlicher, wenn die Brutwaben mehr als 1000 Zellen enthalten (mit Brut : Mittelwert $=1,31 \pm 0,45, \mathrm{n}=45 ;$ ohne Brut : Mittelwert $=1,00 \pm 3,8$, $\mathrm{n}=82$, df $=46, \mathrm{p}<0,001$ ). Es besteht allerdings kein deutlicher Zusammenhang zwischen dem rel. Bienenbefall und dem rel. Brutbefall der Waben. Die lineare Regression vom normierten rel. Brutbefall auf den normierten rel. Bienenbefall $(y=0,05 \cdot x+1,15, \quad r=0,12, \quad N=137)$ steigt zwar leicht an, die Korrelation ist aber nicht signifikant.

3) Noch deutlicher war eine Konzentration des Milbenbefalls zur Mitte hin bei $20 \mathrm{im}$ Herbst (Serie 5) untersuchten Völkern mit beginnender Wintertraubenbildung. Hier wurden pro Volk zwei Bienenproben von ca. 300 Bienen entnommen, jeweils eine von einer mittleren Wabe und eine von einer randständigen Wabe. Der rel. Bienenbefall war im Durchschnitt auf den Mittelwaben 1,5 mal höher als auf Randwaben (t-Test für Paardifferenzen, $\mathrm{p}<0,001$ ).

\section{Abschätzung des Gesamtbefalls aus dem relativen Befall von Brutproben}

\section{a) Berechnungsformel}

Wie bei den Bienenproben korreliert auch bei den Brutproben (Serie 1,2,3) der relative Befall in den Brutproben ( $\mathrm{rBru}=$ Anzahl Varroa/Anzahl verdeckelter Brutzellen) deutlich und signifikant mit der Gesamtzahl von Varroa im Volk (gV; $r=0,57, p<0,001)$. Der niedrige Korrelationskoeffizent weist auf die starken Streuungen hin. Dieser Zusammenhang wird durch die lineare Regression $\mathrm{y}=9,06 \cdot 10^{-5} \cdot \mathrm{x}+0,03$ beschrieben. Als geeignete Schätzformel für den $\mathrm{Ge}-$ samtbefall aus dem rel. Probenbefall wurde entsprechend der Berechnung aus dem rel. Bienenbefall eine Gerade durch den Nullpunkt mit der Formel $\mathrm{GA}=\mathrm{Bruf} \cdot \mathrm{rBru} \cdot \mathrm{z}$ angenommen $(\mathrm{GA}=$ geschätzte Anzahl von Varroa im Volk, $\mathrm{rBru}=$ relativer Brutprobenbefall, $\mathrm{z}=$ Anzahl von Zargen in den Magazinbeuten). Der Brutprobenumrechnungsfaktor (Bruf) wurde so gewählt, daß sich eine möglichst geringe Standardabweichung der Schätzwerte von den tatsächlichen Befallswerten ergab (Bruf $=7500$; Standardabweichung im logarithmischen System $=0,40$ gegenüber 0,42 bei Verwendung der linearen Regression). 
b) Schätzgenauigkeit

In Fig. 4 sind die nach der Schätzformel erhaltenen Schätzwerte gegen den tatsächlichen Befall im logarithmischen Maßstab aufgetragen. Für die einzelnen Völker sind entsprechend zu Fig. 2 Mittelwerte und $95 \%$ Vetrauensbereiche für die Schätzungen aus den einzelnen Brutproben eingezeichnet. Die Mittelwerte enthalten je nach Brutmenge unterschiedlich viele Einzelwerte, im Durchschnitt aber etwa 10. Die Größe des Vertrauensbereiches wird im logarithmischen System von der Höhe des tatsächlichen Befalls nicht deutlich beeinflusst und beträgt im Schnitt $\pm 0,60$, also eine Gesamtspanne von 1,2 Zehnerpotenzen. Bereits die

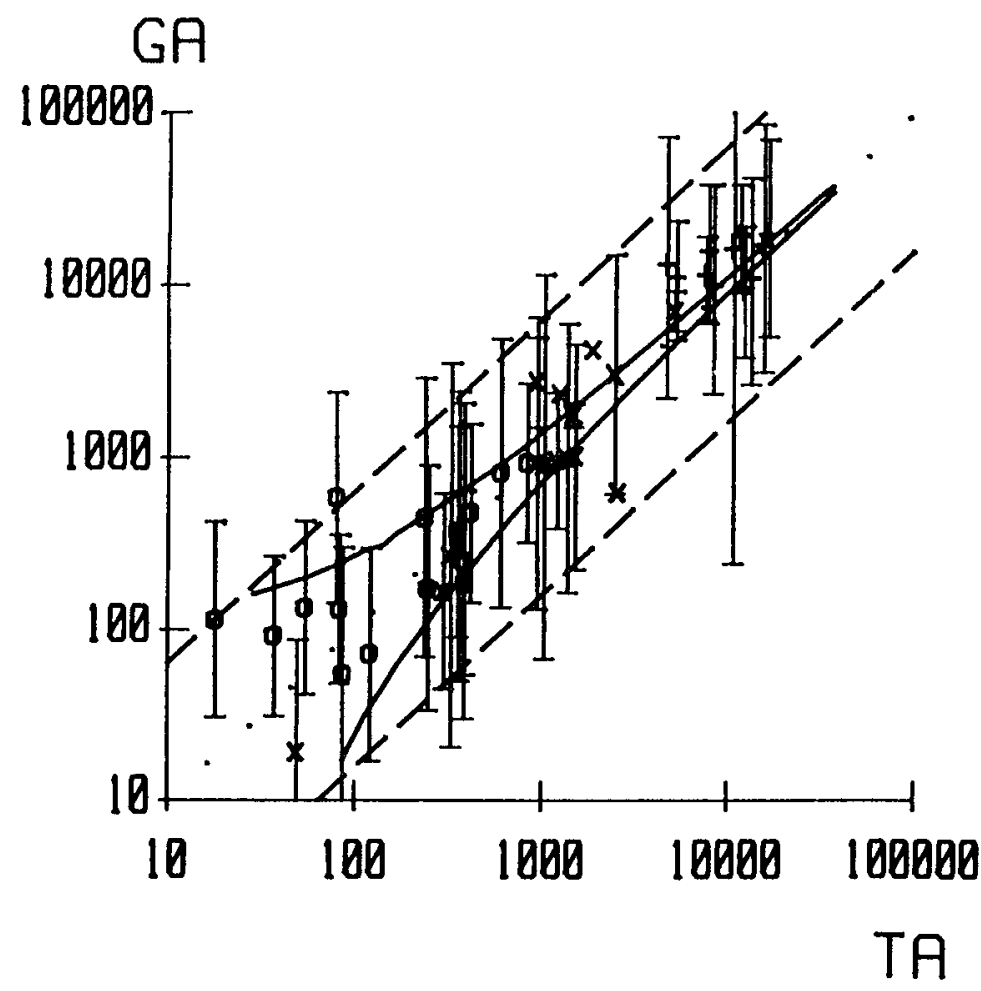

Авв. 4. - Schätzung des Gesamtbefalls der Völker aus Arbeiterbrutproben

(Serie $1:+, 2: \times, 3:$ o). Mittelwerte und $95 \%$ Vertrauensbereiche (ca. 10 Proben/Volk). Abszisse : Tatsächliche Anzahl Varroamilben (TA). Ordinate : Geschätzte Anzahl (GA). Gestrichelte Linien : $95 \%$ Vertrauensbereiche aller Einzelschätzwerte. Durchgezogene Linien : $95 \%$ Vertrauensbereich bei zufällige Streuung des Probenbefalls (Probenumfang von 350 Zellen).

FIG. 4. - Estimates from worker cell samples of the infestation of bee hives

(Series 1: + , series 2: $X$, series 3: o). Means and $95 \%$ confidence intervals (approx. 10 samples/hive). Abscissa : actual number of mites in the hives (TA). Ordinate : estimated number of mites (GA). Broken lines : $95 \%$ confidence interval of all samples combined. Solid lines : $95 \%$ confidence interval with chance deviations of sample infestation (sample size $=350$ cells). 
aus verschiedenen Brutproben des gleichen Volkes gewonnenen Schätzwerte streuen damit über einen sehr weiten Bereich. Auch die Mittelwerte selbst weisen erhebliche Abweichungen von den tatsächlichen Befallswerten auf. Der $95 \%$ Vertrauensbereich für die Mittelwerte überspannt mit $\pm 0,72$ einen noch weiteren Bereich als die Schwankungen innerhalb der einzelnen Völker. Dies weist auf erhebliche Unterschiede zwischen den Völkern hin.

Insgesamt ergibt sich ein $95 \%$.Vertrauensbereich von $\pm 0,80$ für die Schätzungen aus den Einzelproben entsprechend dem Bereich zwischen den durchgezogenen Linien. Damit liegt insgesamt jede zwanzigste Schätzung oberhalb oder unterhalb cines Bereiches, der 1,6 Zehnerpotenzen umfasst. Der Bereich zwischen den gepunkteten Linien gibt wieder den zu erwartenden Vertrauensbereich an, der sich bei einer Probenstärke von 350 Zellen bei nur zufälligen Schwankungen der Varroaanzahlen errechnet (Poisson-Verteilung). Wegen der höheren Brutbefallswerte ist dieser Bereich enger als für Bienenproben, die erwartete Schätzgenauigkeit wäre damit sogar noch höher als bei Bienenproben. Für die tatsächlichen Schätzwerte ist im Gegensatz hierzu keine Verbesserung der Schätzgenauigkeit für den höheren Befallswerte zu erkennen. Auch hier ist die Schätzgenauigkeit durch einen konstanten Faktor (untere $95 \%$ Vetrauensgrenze = tatsächlicher Befall $/ 6,3$, obere $95 \%$ Vertrauensgrenze $=$ tatsächlicher Befall $\cdot 6,3$ ) befriedigend gekennzeichnet.

c) Verteilungsunterschiede von Varroa auf Brut als Ursache der Schätzungenauigkeit

1) Unterschiede zwischen den Völkern tragen erheblich zur Ungenauigkeit der Befallsabschätzungen bei. Ein erkennbarer Faktor ist auch bei der Abschätzung aus dem Brutprobenbefall die unterschiedliche Brutmenge in den Völkern. In 44 Völkern aus Serie 1, 2 und 3 waren in der Mehrzahl der Fälle die Mittelwerte der Schätzungen dann zu niedrig, wenn überdurchschnittlich viel Brut vorhanden war (14:9; Durchschnitt 4700 Zellen). Bei unterdurchschnittlich viel Brut waren die Mittelwerte in der Mehrzahl der Fälle zu hoch (18:3, p $<0,025$, Chi²-Test).

2) $\mathrm{Zu}$ den abweichenden Schätzungen aus den Brutproben eines Volkes trägt - anders als bei den Bienenproben — die Position der Brutwabe in keiner erkennbaren Weise bei (Fig. 3). In Serie 1 ist der am Gesamtbefall des Volkes normalisierte relative Brutbefall der vier mittleren Waben im Schnitt zwar höher als der der randständigen Waben, aber dieser Unterschied ist wegen der großen Streuungen nicht signifikant [Mitte (4-7) : Mittelwert $=1,15 \pm 0,72$, $\mathrm{n}=30 ;$ Rand $(1-3,8-10):$ Mittelwert $=0,88 \pm 0,47, \quad \mathrm{~N}=16, \mathrm{t}=1,9$, $\mathrm{df}=18 \mathrm{~ns}$. In Serie 2 ist der normierte relative Brutbefall der mittleren Waben erheblich niedriger als der der randständigen Waben, allerdings ist auch dieser Unterschied nicht sichtbar (Mitte : Mittelwert $=0,98 \pm 0,81, \mathrm{~N}=53$; Rand : Mittelwert $=1,75 \pm 1,65, \mathrm{~N}=17, \mathrm{t}=1,2$, df $=16 \mathrm{~ns}$ ). 
3) Der relative Brutbefall differiert nicht nur von Wabe zu Wabe, sondern ist bereits auf den einzelnen Waben sehr unterschiedlich. Als Beispiel der Verteilung von Varroa ist eine Wabe aus Serie 6 in Fig. 5 dargestellt, deren Zellen einzeln geöffnet und auf adulte Varroa untersucht wurden. Die ältesten Larvenstadien der Arbeiterinnen entsprachen einer Verdeckelungszeit von etwa 8-10 Tagen (Puppen mit lila Augen), sodaß überwiegend Infektionszahlen erfasst wurden. Es ist unmittelbar zu sehen, daß der Befall der Wabe in Bezirken konzentriert ist. Werden immer 7 Zellen zu einer Einheit zusammengefasst, so weicht die Verteilung von Varroa auf diese 7er-Blocks signifikant von der bei gleichmäßigem Befall zu erwartenden Poissonverteilung ab (Chi²-Test, $\mathrm{p}<0,01)$. Das Ergebnis einer Auswertung von 2 weiteren Waben ist in Tab. 2 dargestellt. Für diese war nach dem gleichen Verfahren ebenfalls ein ungleichmäßiger Befall sichtbar. Auf allen drei Waben ist ein unterschiedlich hoher relativer Befall der einzelnen Brutstadien (Larve, Puppe mit weißen Augen und Puppe mit lila Augen) deutlich. Interessanterweise besteht zwischen dem rel. Befall der beiden Wabenseiten der gleichen Wabe ebenfalls keine enge Beziehung, weder insgesamt noch in Hinblick auf die einzelnen Brutstadien.

Für die Völker aus Serie 3 ergibt sich eine nachweisliche Bevorzugung von Varroa für die Mittelzone der Waben. 38 der größeren Brutbereiche waren in 4 Randzonen und 1 Mittelzone unterteilt. Der mittlere relative Befall der Mittelstücke überstieg mit 0,025 den der Randstücke $(0,021)$ und war signifikant häufiger über dem Wabenmittel als der der Randstücke (Chi'2-Test, p < 0,001). Für 15 Waben aus Serie 1 ergaben sich keine sicheren Befallsunterschiede in Hinblick auf die Position der Wabenteilstücke.

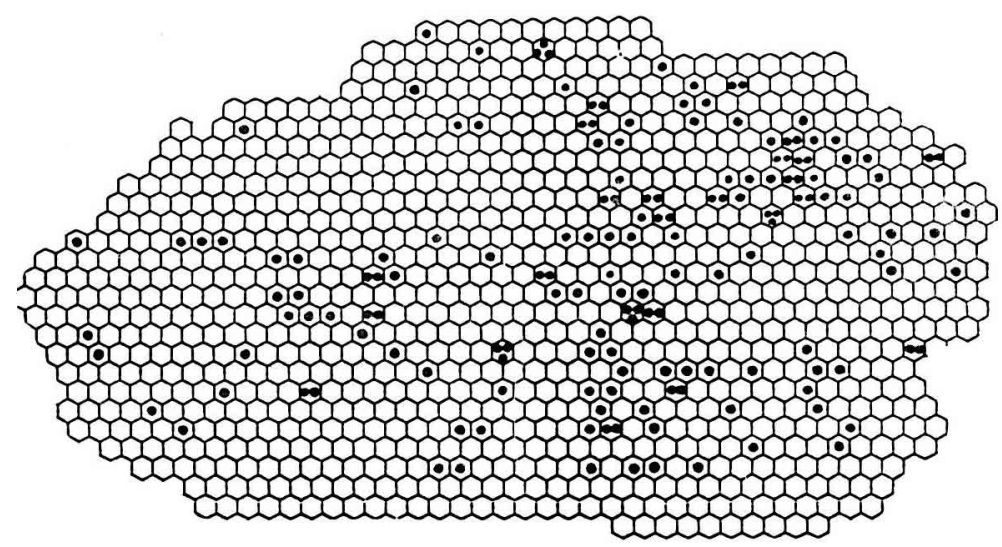

Aв8. 5. - Räumliche Verteilung von eingedrungenen Varroamilben (.) in eine Arbeiterinnenbrutwabe

FIG. 5. - Spatial distribution of cells infested by Varroa mites (.) on a worker brood comb. 
4) Auch die Anzahl von Varroa in den einzelnen Zellen weicht deutlich von der bei zufälliger Belegung zu erwartenden ab. Das Ergebnis der Auswertung der 65 Wabenstücke aus Serie 6 mit jeweils ca. 100 Zellen ist in Fig. 6 dargestellt. Die Histogramme geben die Häufigkeiten an, mit denen 0, 1, 2, etc. Varroa eine Zelle infiziert hatten. Hierbei wurden die Proben nach ihrem relativen Gesamtbefall in 4 Kategorien eingeteilt. Da im Hinblick auf diese Verteilungen kein prinzipieller Unterschied zwischen Drohnenzellen und Arbeiterinnenzellen gefunden wurde, sind beide Bruttypen hier zusammen dargestellt. Verglichen mit den für den mittleren Befall der Brutstiucke des jeweiligen Diagramms errechneten Poissonverteilungen zeigt sich eine mit steigendem Befall immer deutlichere Tendenz zu geringeren Häufigkeiten der mittleren Anzahlen von Varroa pro Zelle zugunsten der höheren und geringen Anzahlen. Bei einem rel. Brutbefall von $\mathrm{rBru}=1$ sind 6 von 24 , bei $1<\mathrm{rBru} \leqslant 2$, 15 von 26 , bei $2<\mathrm{rBru} \leqslant 5$, 8 von 12 und bei $\mathrm{rBru}>5,3$ von 3 der Verteilungen signifikant auf mindestens dem $5 \%$-Level von der dem rel. Befall der jeweiligen Brutprobe zuzuordnenden Poissonverteilung verschieden (Chi²-Tests).

ТАВ. 2. - Ungleichmäßige Verteilung des Befalls von Brutwaben mit Varroa

TABL. 2. - Irregular distribution of varroa infestation on brood combs

\begin{tabular}{|c|c|c|c|c|}
\hline $\begin{array}{l}\text { Wabe } \\
\text { Comb }\end{array}$ & $\begin{array}{c}\text { Zellen } \\
\text { Brood cells }\end{array}$ & $\begin{array}{l}\text { Varroa } \\
\text { Varroa }\end{array}$ & $\begin{array}{c}\text { Rel. Befall } \\
\text { Rel. infestation }\end{array}$ & $\begin{array}{c}\text { Signifikanz } \\
\text { Stat. significance }\end{array}$ \\
\hline $1 \mathrm{a}$ & 860 & 179 & 0,21 & $\mathrm{Chi}^{2}=14,7, \mathrm{df}=3, \mathrm{p}<0,01$ \\
\hline Lv & 308 & 29 & 0,09 & Lv vs. $P w: p<0,001$ \\
\hline Pw & 284 & 82 & 0,29 & Pw vs. $\mathrm{Pd}: \mathrm{p}$ ns \\
\hline$P d$ & 268 & 68 & 0,24 & Pd vs. Lv : p $<0,001$ \\
\hline $1 \mathrm{~b}$ & 993 & 136 & 0,14 & $\mathrm{Chi}^{2}=11,3, \mathrm{df}=2, \mathrm{p}<0,01$ \\
\hline $\mathrm{Lv}$ & 630 & 73 & 0,12 & Lv vs. $\mathbf{P w}: \mathrm{ns}$ \\
\hline Pw & 159 & 9 & 0,06 & Pw vs. $P d: p<0,001$ \\
\hline $\mathrm{Pd}$ & 194 & 54 & 0,28 & Pd vs. Lv : $p<0,001$ \\
\hline 2 & 611 & 170 & 0,28 & $\mathrm{Chi}^{2}=14,2$, df $=5, \mathrm{p}<0,02$ \\
\hline Lv & 436 & 99 & 0,23 & Lv vs. $P w: p<0,01$ \\
\hline Pw & 157 & 61 & 0,39 & Pw vs. $\mathrm{Pd}: \mathrm{ns}$ \\
\hline $\mathbf{P d}$ & 18 & 10 & 0,56 & Pd vs. Lv : $p<0,02$ \\
\hline
\end{tabular}

Chi $^{2}$-Test : Abweichungen von Varroaanzahlen aus jeweils 7 benachbarten Zellen gegen Poissonverteilung. Entwicklungsstadien der Bienenbrut : Larve (Lv), Puppe mit weißen Augen (Pw), Puppe mit dunklen Augen (Pd).

Chi2-test : deviation of numbers of mites within 7 adjacent cells from poisson-distribution. Stages of brood development : larva (Lv), white-eyed pupa (Pw), dark-eyed pupa (Pd). 

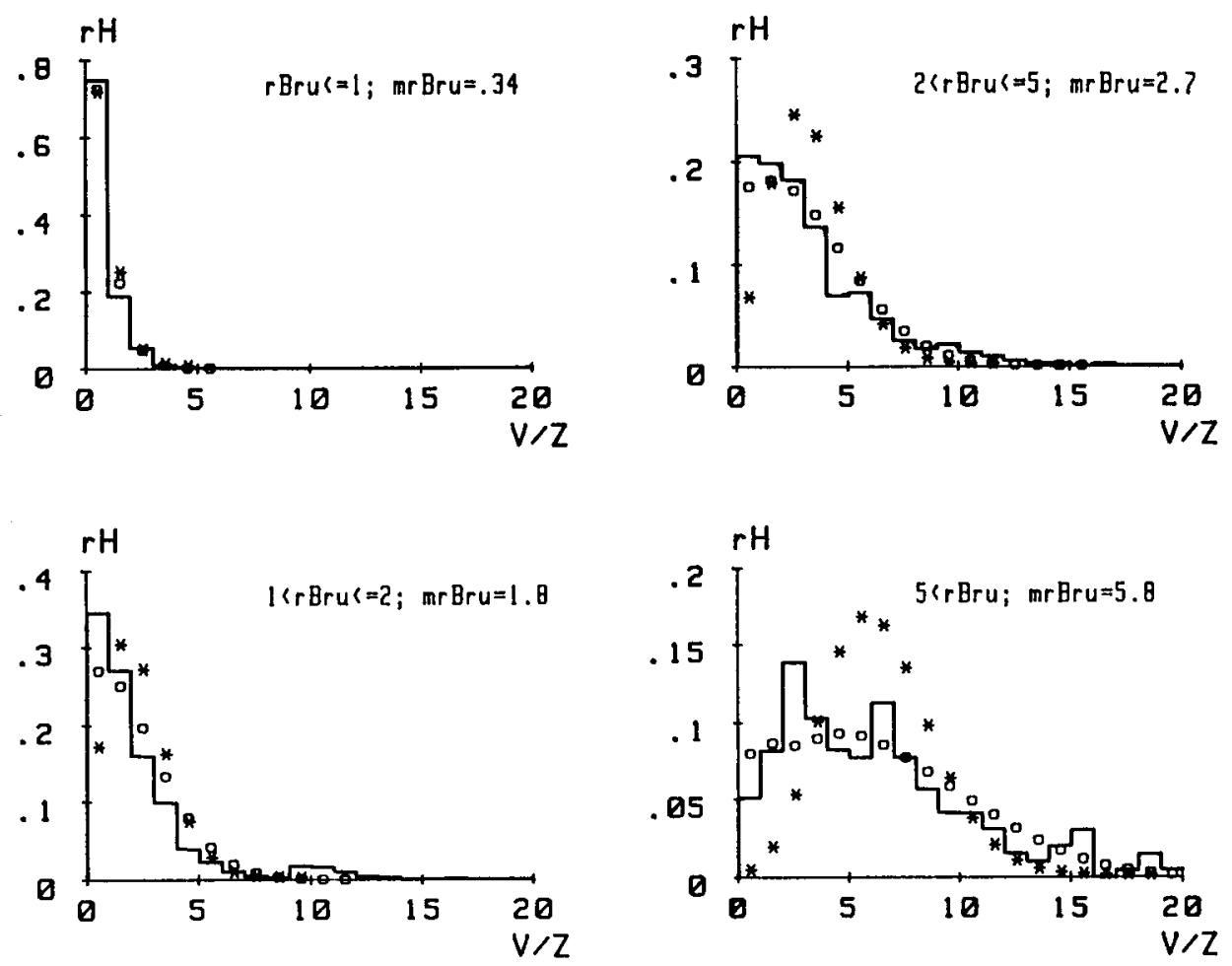

Aвв. 6. - Anzahlen von Varroa in einer Zelle

65 Brutproben mit jeweils ca. 100 Zellen, Serie 6. Abszisse : Varroa/Zelle (V/Z). Ordinate : rel. Häufigkeit des Zellenbefalls (rH, durchgezogene Linie). rBru = relativer Befall der Probenstücke. Sterne : Dem mittleren Befallsgrad der Proben (mrBru) entsprechende Zufallsverteilung (Poissonverteilung). Offene Kreise : Verteilung entsprechend Modellrechnung (siehe Text).

FIG. 6. - Frequencies of mite numbers in single cells

65 brood samples containing approx. 100 cells each, series 6. Abscissa : varroa/cell (V/Z). Ordinate : relative frequencies of cell infestation $(\mathrm{rH}$, solid line). $\mathrm{rBru}=$ cell infestation rate of the samples. Asterisks : Random distribution of mites according to the mean infestation of the samples (mrBru, Poisson-distribution). Open circles : distribution according to model calculation (see text).

\section{Verteilung von Varroa auf Brut und auf Bienen}

Abweichungen der Hochrechnungsergebnisse zwischen den Völkern wiesen sowohl bei Bienenproben, als auch bei Brutproben eine Beziehung zur vorhandenen Brutmenge auf. Dies weist darauf hin, daß Unterschiede der Verteilung der Varroapopulation zwischen Bienen und Brut von Bedeutung sind. Diese Verteilung wurde unter Berücksichtigung der Serien 1, 2 und 3 untersucht (45 Völker). Mit steigendem relativen Bienenbefall der ganzen Völker steigt auch der relative Brutbefall (Fig 7 a). Der Zusammenhang wird durch die lineare Re- 

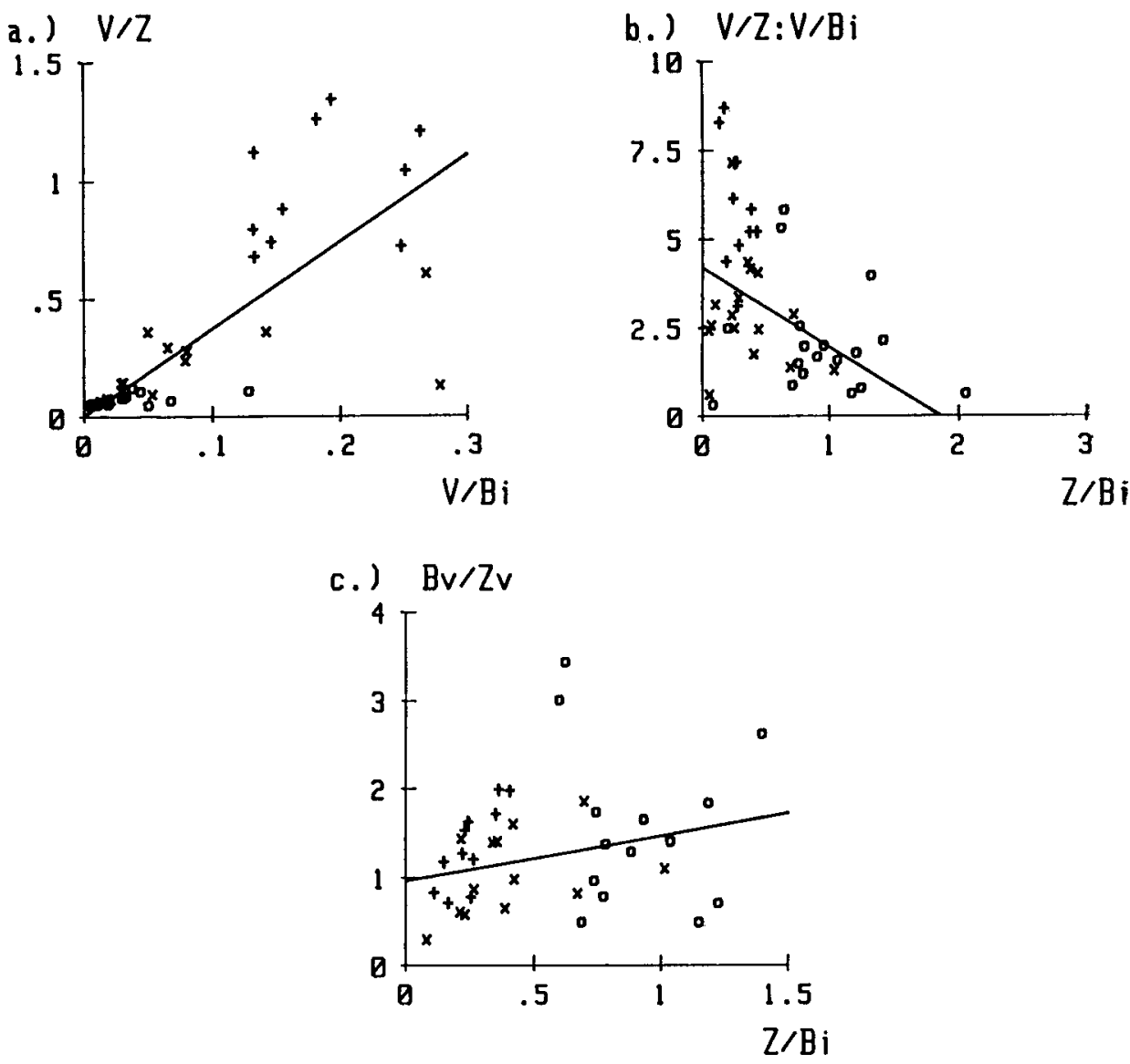

Aвв. 7. - Verteilung der Varroapopulation auf Bienen und Brut

(Serie $1: \times, 2:$ o, $3:+$ ). Durchgezogene Linien : Lin. Regression. a) Abszisse : Rel. Bienenbefall (Varroa/Bienen, V/Bi) ; Ordinate : rel. Brutbefall (Varroa/Brutzellen, V/Z). b) Abszisse : Rel. Brutangebot (Brutzellen/Bienenanzahl, Z/Bi), Ordinate : Rel. Brutbefall/rel. Bienenbefall (V/Z : $\mathrm{V} / \mathrm{Bi}$ ). c) Abszisse : Rel. Brutangebot (Brutzellen/Bienenanzahl, ZBi), Ordinate : Varroa in Brutzellen/Varroa auf Bienen $(\mathrm{Bv} / \mathrm{Zv})$.

FIG. 7. - Distribution of Varroa mites between bees and brood cells

(Series $1: \times, 2: \mathbf{o}, 3:+$, solid lines : lin. regression). a) Abscissa : rel. bee infestation (varroa/bees, V/Bi), ordinate : rel. brood infestation (varroa/brood cells, V/Z). b) Abscissa : rel. brood abundance (brood cells/bees, $Z / B i$ ), ordinate : rel. brood infestation/rel. bee infestation (V/Z : V/Bi). c) Abscissa : rel. brood abundance (brood cells/bees, Z/Bi), ordinate : varroa in brood cells/varroa on bees $(\mathrm{Bv} / \mathrm{Zv})$.

gression $\mathrm{rBru}=3,7 \cdot \mathrm{rBi}+0,004$ angenähert. Der relative Brutbefall ist damit im Schnitt etwa 4 mal so groß wie der rel. Bienenbefall. Der Zusammenhang ist zwar signifikant $(r=0,76, p<0,001)$ aber außerordentlich lose, was sich in dem 
niedrigen Korrelationskoeffizienten ausdrückt. Rückschlüsse von dem rel. Bienenbefall auf den rel. Brutbefall sind daher sehr unsicher.

Ein offensichtlicher Einflußfaktor hierbei ist die Brutmenge, also das Verhältnis von Brutzellen zu Bienen. Je weniger Brut relativ zur Bienenanzahl vorhanden ist, umso größer ist das Verhältnis von rel. Brutbefall zu rel. Bienenbefall (Fig. 7 b). Bei sehr wenig Brut übersteigt der rel. Brutbefall den rel. Bienenbefall um mehr als das vierfache und sinkt bei überwiegen der Brutzellenzahl über die Bienenzahl bis unter den rel. Bienenbefall. Die Korrelation ist trotz der erheblichen Streuungen signifikant $(r=0,45, p<0,01)$.

Solange nicht sehr wenig Brut im Volk vorhanden ist $(<500$ Zellen), kann man in etwa davon ausgehen, daß sich im Mittel die Hälfte der Varroa auf den Bienen, die andere Hälfte in der Brut befinden. Dies Verhältnis wird nur geringfügig von der vorhandenen Brutmenge beeinflußt (Fig. $7 \mathrm{c}$ ). Die lineare Regression von dem Verhältnis von Brutzellen zu Bienen auf das Verhältnis von Varroa in Brutzellen zu Varroa auf Bienen steigt zwar leicht an, die Korrelation ist aber nicht signifikant $(\mathrm{y}=0,51 \cdot \mathrm{x}+0,96, \mathrm{r}=0,25)$. Wieder ist die Variabilität außerordentlich groß, sodaß bei etwa gleichem Verhältnis von Brut zu Bienen in einem Volk dreimal mehr Varroa in der Brut gefunden wurden als auf den Bienen, in einem anderen Volk zur gleichen Jahreszeit aber nur ein Drittel.

IV. Abschätzung des Gesamtbefalls aus einer Kombination des relativen Befalls von Bienenproben und Brutproben

Um den Einfluß unterschiedlicher Verteilungen der Milben auf Bienen oder Brut teilweise auszugleichen, wurde versucht durch die Kombination der Schätzung aus dem rel. Brutbefall mit der Schätzung aus dem rel. Bienenbefall eine Verbesserung der Schätzgenauigkeit zu erreichen. Von Serie 1 und 2 wurde von jeder Brutwabe der rel. Brutbefall (bei Serie 1 unter Verwendung von nur einer der bis zu 5 Brutproben aus einer Wabe) und der rel. Bienenbefall der Bienen von der gleichen Wabe in die Berechnung eingesetzt. Als Schätzformel diente wieder eine Gerade durch den Nullpunkt entsprechend der Formel $\mathrm{GA}=(\mathrm{Bif} \cdot \mathrm{rBi}+\mathrm{Bruf} \cdot \mathrm{rBru}) \cdot \mathrm{z}(\mathrm{GA}=$ geschätzte Gesamtvarroa im Volk, $\mathrm{rBi}=$ rel. Bienenbefall der Probe, $\mathrm{rBru}=$ rel. Brutbefall der Probe, $\mathrm{z}=$ Anzahl der Zargen der Magazinbeute). Als Umrechnungsfaktoren für die Bienenproben $($ Bif $=10000)$ und die Brutproben $($ Bruf $=3000)$ wurde durch wiederholte Berechnung die Wertekombination bestimmt, mit der sich im logarithmischen System eine minimal Standardabweichung des geschätzten Befalls von dem tatsächlichen Befall erreichen ließ. Die Breite des mit dieser Formel erreichten $95 \%$ Vertrauensbereichs beträgt $\pm 0,44$. Im linearen System entspricht dies einer unteren Vertrauensgrenze von tatsächlichem Befall / 2,75 und einer oberen Vertrauensgrenze von tatsächlichem Befall $\cdot 2,75$. 
Eine weitere Verbesserung der Zuverlässigkeit ist möglich, wenn Volksstärke und Brutmenge in die Berechnungen einbezogen werden. Durch Einsetzen von Bienenanzahl (Biz) und Zellenanzahl (Bruz) in die Schätzformel $\mathrm{GA}=\mathrm{rBi} \cdot \mathrm{Biz}+\mathrm{rBu} \cdot$ Bruz ergibt sich ein $95 \%$ Vertrauensbereich von $\pm 0,37$ im log. System entsprechend einem Bereich mit der unteren Grenze von tatsächlichem Befall / 2,34 und der oberen Grenze von tatsächlichem Befall ·2,34 im linearen System.

\section{DISKUSSION}

\section{Abschätzung des Varroabefalls}

Die Ergebnisse zeigen, daß aus Bienenproben oder Brutproben eine Abschätzung des Gesamtbefalles eines Volkes mit Varroa zwar im Prinzip möglich ist, daß aber wegen sehr großer Streuungen sowohl zwischen einzelnen Proben aus einem Volk als auch zwischen den Völkern relativ oft mit gravierenden Fehldiagnosen zu rechnen ist. Damit können beide Verfahren in der Praxis zwar Hinweise auf die Befallsstärke liefern, sie stellen aber kein verläßliches Bestimmungsverfahren dar. Bei einem tatsächlichen Befall des Volkes mit 1000 Milben fällt bei einer Befallsschätzung aus Bienenproben im Schnitt jeder 20. Schätzwerte geringer als 263 oder größer als 3802 Milben aus, bei einer Schätzung aus Brutproben geringer als 158 oder größer als 6300 (vgl. Tab. 3). Die Schätzung aus Bienenproben ist damit um etwa $40 \%$ zuverlässiger als die Schätzung aus Brutproben.

Eine weitere Verbesserung lässt sich durch die Kombination von einer Bienenprobe mit einer Brutprobe erreichen. Dies berücksichtigt, daß sich außerordentlich unterschiedliche Anteile der Varroapopulation auf den Bienen oder in der Brut befinden können. Die oben angegebenen Grenzwerte des $95 \%$ Vertrauensbereichs betragen dann 364 bzw. 2750 Varroa. Hiermit ist gegenüber der Schätzung aus Bienenproben allein die Zuverlässigkeit um $28 \%$ größer, was den größeren praktischen Aufwand rechtfertigt. Da aber auch jetzt noch ca. ein Sechstel aller Schätzwerte mehr als um die Hälfte oder das Doppelte vom tatsächlichen Befall abweicht, ist auch dieses kombinierte Verfahren von noch unbefriedigender Genauigkeit. Eine Fortenwicklung durch Einbeziehung von Schätzwerten für die Volksstärke und die Brutmenge bringt allerdings keine wesentlich genaueren Ergebnisse mehr. Durch Einsetzen der tatsächlichen Bienenanzahlen und Zellenanzahlen war die Zuverlässigkeit gegenüber dem kombinierten Verfahren um nur noch $15 \%$ zu steigern.

Die bisher üblichste Schätzmethode ist die Beurteilung der Befallsstärke aus dem natürlichen Milbenfall. Hierbei dient die Anzahl der aus dem Volk auf ein 
TAB. 3. - Zuverlässigkeit der Abschätzungsverfahren

TABL. 3. - Reliability of estimates

\begin{tabular}{|c|c|c|c|c|}
\hline \multirow[t]{2}{*}{$\begin{array}{l}\text { Schätzung des Befalls durch } \\
\text { Hive infestation estimated by }\end{array}$} & \multicolumn{2}{|c|}{$\begin{array}{c}95 \% \text { Vertrauens- } \\
\text { bereich } \\
95 \% \text { confidence } \\
\text { interval }\end{array}$} & \multicolumn{2}{|c|}{$\begin{array}{c}95 \% \text { Vertrauens- } \\
\text { grenzen } \\
95 \% \text { confidence } \\
\text { limits }\end{array}$} \\
\hline & $\mathrm{v}$ & f & $\mathrm{uG}$ & $o G$ \\
\hline $\begin{array}{l}\text { Brutproben } \\
\text { Brood cell samples }\end{array}$ & 0,80 & 6,3 & 158 & 6300 \\
\hline $\begin{array}{l}\text { Bienenproben } \\
\text { Bee samples }\end{array}$ & 0,58 & 3,8 & 263 & 3802 \\
\hline $\begin{array}{l}\text { Brutproben und Bienenproben } \\
\text { Brood cell samples and bce samples }\end{array}$ & 0,44 & 2,8 & 364 & 2750 \\
\hline $\begin{array}{l}\text { Brutproben, Bienenproben, Bienenzahl und Zellenzahl } \\
\text { Brood cell samples, bee samples, bees in hive and cells in } \\
\text { hive }\end{array}$ & 0,37 & 2,3 & 427 & 2340 \\
\hline $\begin{array}{l}\text { Tägl. natürlicher Milbenfall (LIEBIG, 1984) } \\
\text { Natural fall of dead mites (LIEBIG, 1984) }\end{array}$ & 0,41 & 2,57 & 389 & 2570 \\
\hline
\end{tabular}

$95 \%$ Vertrauensbereiche im logarithmischen (v) und linearen ( $f=10 \mathrm{v}$ ) Maßstab, untere $(\mathrm{uG}=1000 / \mathrm{f})$ und obere $(\mathrm{oG}=1000 . \mathrm{f}) 95 \%$ Vetrauensgrenze bei angenommenen Befall mit 1000 Varroa.

$95 \%$ confidence intervals in logarithmic (v) and linear ( $f=10 \mathrm{v}$ ) measure, lower (uG $=1000 / \mathrm{f}$ ) and upper (oG $=1000 . \mathrm{f}$ ) $95 \%$ confidence interval with an assumed hive infestation of 1000 mites.

unten in die Beute eingelegtes Papier abfallenden Milben als Berechnungsgrundlage. Über die Zuverlässigkeit der Methode liegen wenige Angaben vor. Am besten gesichert ist bisher eine Korrelation des natürlichen täglichen Milbenfalls im Spätsommer (September-Oktober) mit der Befallsstärke des Volkes bei der Herbstbehandlung (Liebig et al., 1984). Die Untersuchungen stützen sich auf den jeweils höchsten Wert bei wöchentlichen Ablesungen und führten zu einer Einschätzung der Befallsstärke als dem 120-fachen des höchsten Milbenfalls pro Tag. Hierbei wurde ein Standardfehler von $\pm 0,206$ im logarithmischen System angegeben. Dies entspricht bei 43 untersuchten Völkern einem $95 \%$ Vertrauensbereich von $\pm 0,41$ oder bei einem tatsächlichen Befall von 1000 Varroa der Erwartung, daß im Schnitt jeder 20. Schätzwert kleiner als $1000 / 2,6=389$ oder größer als $1000 \cdot 2,6=2600$ ausfällt. Die Methode ist damit nur um weniges zuver- 
lässiger $(6 \%)$ als das kombinierte Schätzverfahren aus Bienenproben und Brutproben. In der Praxis dürfte die Anwendbarkeit eingeschränkt sein durch die Notwendigkeit wiederholter Ablesungen des Windelfalls sowie durch die Einschränkung auf einen festgelegten Jahresbereich. Der natürliche Milbenfall ist stark von der Reproduktion der Milben und damit auch von der Bruttätigkeit der Völker beeinflußt. Nach überschlägigen Berechnungen für die Völker aus Serie 3 (April), für die der natürliche Milbenfall bekannt war, führte ein Umrechnungsfaktor von etwa $800 \mathrm{zu}$ den besten Ergebnissen. Entsprechende Unterschiede bei den Umrechnungsfaktoren sind auch von Jahr zu Jahr auf Grund unterschiedlichen Wetterverlaufs oder von Standort zu Standort zu vermuten.

Es dürfte damit deutlich geworden sein, daß der Sprung zu einer ausreichend zuverlässigen Schätzmethode mit einer Weiterentwicklung der bisherigen Ansätze nicht zu erreichen sein dürfte. Es erscheint wenig sinnvoll, weitere Bienenvölker in dieser Richtung zu investieren. Erfolgversprechender ist, durch die Untersuchung der biologischen und populationsdynamischen Faktoren eine genauere Kenntnis des Parasiten und damit auch der eigentlichen Ursachen der Streuungen zu erhalten. Solange keine wesentlich zuverlässigere Methode ausgearbeitet worden ist, bleibt man jedoch auf die vorhandenen Verfahren angewiesen. Gegenüber reinem Raten stellen sie dennoch einen erheblichen Fortschritt dar. Nur $4 \%$ von 12000 zufällig verteilten Schätzwerten zwischen 0 und 15000 (höchster Befall bei den untersuchten Völkern $=16560$ Varroa) fielen in einen akzeptablen Bereich von tatsächlichem Befall $\pm 10 \%$, während es nach dem kombinierten Schätzverfahren aus Bienenproben und Brutproben immerhin $15 \%$ waren. Unter Abwägung zwischen Aufwand und der erforderlichen Aussagesicherheit kann durch wiederholte Anwendung der gleichen oder Kombination mehrerer der vorhandenen Methoden der tatsächliche Befall wenigstens angenähert werden. Bei angemessen vorsichtiger Interpretation können die erhaltenen Schätzwerte dann durchaus von Nutzen sein.

\section{Verteilung der Varroa in Bienenvolk}

\section{a) Verteilung zwischen Bienen und Brut}

Die Anteile der Varroapopulation, die sich auf den Bienen oder in der verdeckelten Brut befinden sind so variabel, daß sich Gesetzmäßigkeiten nur mit Mühe sicherstellen lassen. Es ist ein interessantes Ergebnis, daß oberhalb einer Mindestbrutmenge von nur 500-1 000 Zellen der Anteil der Varroapopulation in der Brut kaum noch zunimmt. Dies zeigt, daß immer nur ein gewisser Teil der Varroapopulation bereit ist, zur Reproduktion in die Zellen zu gehen, wie dies auch von Schulz (1984) gefunden wurde. Es überrascht demnach auch nicht, daß relativer Bienenbefall und relativer Brutbefall in nur sehr losem Zusammenhang stehen. Ganz offensichtlich und in Übereinstimmung mit den Ergebnissen von 
HÄNEL $(1983,1985)$ benötigt Varroa, um von den Bienen in Reproduktion gehen zu können, spezifischer Auslöser. Hierdurch bleibt ein Anteil der Population auch dann außerhalb der Zellen, wenn genügend Brut vorhanden ist und das Auffinden einer geeigneten Zelle keinen begrenzenden Faktor darstellt. Zusätzlich sind die Anteile der Milbenpopulation, die in die Brut gehen, auch bei gleichen Brutmengen von Volk zu Volk außerordentlich unterschiedlich. Dies weist auf komplizierte Interaktionen zwischen Varroa und dem Bienenvolk hin, die zu verstehen von praktischer Bedeutung sein könnte.

\section{b) Verteilung von Varroa auf den Bienen}

Im Gegensatz zu den Milbenverteilungen zwischen Bienen und Brut oder auf der Brut ist die Ermittlung der Verteilung auf die Bienen methodisch weitaus unsicherer. Durch die Unruhe beim Abfegen der Völker kann die ursprüngliche Verteilung verändert sein, wahrscheinlich in Richtung einer stärkeren Durchmischung. Dies sollte zu einer Verbesserung der Hochrechnungsergebnisse bei einer Verwischung der Verteilungscharakteristik führen.

Aus den Versuchsdaten ergab sich übereinstimmend ein etwas höherer relativer Bienenbefall auf den Mittelwaben der Völker. Dies dürfte auf den nachweislich höheren Befall der im Innenbereich häufigeren Jungbienen, vor allem der Ammenbienen, zurückzuführen sein. Dieser wurde zuletzt von Kraus (1985) nachgewiesen und als gegenüber Flugbienen 2-3 fach höher eingeschätzt. Übereinstimmend hiermit zeigten in meinen Untersuchungen die nach der Entnahme der Waben in den Beuten zurückbleibenden Bienen einen im Durchschnitt um $15 \%$ niedrigeren rel. Befall als die Bienen auf den Waben (Serie 1).

Der höhere Befall der Bienen auf Brutwaben ist sicher zum Teil auf die Position der Brutwaben in der Mitte der Beuten zurückzuführen. Teilweise ist er aber auch durch die Anwesenheit von Brut selbst bedingt, da Waben aus dem Mittelbereich mit Brut stärker befallen waren als Waben ohne Brut, wobei die Brutmenge auf den Waben allerdings keinen deutlichen Einfluß ausübte. Es bleibt offen, ob ein Einfluß durch die Brut selbst ausgeübt wird oder z.B. allein durch einen höheren Anteil von Ammenbienen auf den Brutwaben.

Verhältnismäßig deutlich war auch eine höhere Konzentration von Varroa im Mittelbereich bei beginnender Wintertraubenbildung. Dies weist darauf hin, daß sich Varroa in den Wintertrauben möglicherweise stark zur Mitte hin orientiert. Dies könnte auf eine Vermeidung der kühleren Temperaturen in den Randbereichen zurückzuführen sein. Insgesamt ist keiner der angeführten Verteilungsparameter von seiner Größenordnung her geeignet, die Streubreite der Hochrechnungsergebnisse zu erklären, sodaß offensichtlich zusätzliche Varroadichteschwankungen unbekannten Ursprungs eine Rolle spielen. 


\section{c) Verteilung von Varroa auf der Brut}

Die Verteilung von Varroa auf Brut ist noch unregelmäßiger als die auf Bienen. Die Unregelmäßigkeiten legen die Interpretation nahe, daß an kurz aufeinanderfolgenden Zeitpunkten stark wechselnde Anzahlen von Varroa die kurz vor der Verdeckelung stehenden Zellen aufsuchen. Der Befall richtet sich damit mehr nach dem Zellenangebot und der Anzahl der zu diesem Zeitpunkt reproduktionswilligen Varroae als nach der Position der Zellen. Dies steht damit im Einklang, daß kein verstärkter Befall der Mittelwaben gegenüber den randständigen Waben nachweisbar war.

Auf den Waben finden sich Bezirke von in relativ kurzer Zeit hintereinander bestifteten Zellen. Diese Bezirke sind verschieden stark befallen. Unterschiedliche Entwicklungsstadien auf einer Wabe, aber auch Vorderseite und Rückseite der gleichen Wabe weisen daher sehr unterschiedlichen rel. Brutbefall auf. Der stärkere Befall der Mittelbereiche bei den unterteilten Brutwaben der Serie 3 könnte mit der Situation im Frühjahr (Anfang April) im Zusammenhang gestanden haben. In dieser Phase könnte ein Überhang reproduktionswilliger Varroae in die Anfänge des Brutnestes eingedrungen sein, während für die Randbereiche dann relativ weniger Varroa zur Verfügung standen. Für einen jahreszeitlich bedingten Effekt spricht, daß für die Waben aus Serie 1 (Juli) ein höherer Befall der Wabenmitten nicht gefunden wurde.

Die Häufigkeiten der Infektion der einzelnen Zellen mit einer oder mehreren Varroae wichen von zufälligen Verteilung durch erniedrigte Häufigkeiten mittlerer Varroaanzahlen ab. Eine mögliche Erklärung ist eine erhöhte Attraktivität von bereits mit Varroa befallenen Zellen. Ein ähnlicher Effekt entsteht aber auch, wenn stark wechselnde Varroaanzahlen kleinen Mengen von infizierbaren Zellen gegenüberstehen. Dies demonstriert eine Simulationsrechnung. Es wurde angenommen, daß an 10 aufeinanderfolgenden Zeitpunkten jeweils $10 \%$ der Zellen belegt werden können und von den insgesamt vorhandenen Varroae jeweils wechselnde Prozentsätze in die Zellen gehen $(20,17,1,11,15,6,10,9,3,12 \%)$. Hierdurch kommt es im Hinblick auf die Gesamtheit der Zellen zur Überlagerung mehrerer Poissonverteilungen entsprechend den unterschiedlichen Zahlenverhältnissen zwischen Varroa und Zellen. Die hierdurch erreichten Verteilungen sind für den jeweils entsprechenden rel. Brutbefall in Fig. 6 eingetragen und zeigen hier deutlich die Ähnlichkeit mit den tatsächlichen Verteilungen. Mit einem umgekehrten Ansatz, also stark wechselnden Zellenanzahlen bei gleichbleibenden Anzahlen infektionsbereiter Varroae, können keine vergleichbaren Ergebnisse erzielt werden. Auch dieses Resultat stützt damit die Interpretation, daß die Anzahlen infektionsbereiter Varroae kurzzeitig stark schwanken können. Da Varroa im Prinzip schon nach wenigen Tagen reproduktionsfähig ist (ScHulz, 1984), sind: 


\section{die Bedingungen, unter denen Varroa zur Reproduktion in die Zellen geht ein außerordentlich wichtiger zukünftiger Untersuchungsaspekt.}

Eingegangen im September 1985.

Angenommen im Oktober 1985.

\section{DANKSAGUNG}

Ich danke Herrn Prof. N. Koeniger, der die Durchführung der Arbeiten in jeder Weise unterstützt hat. Weiter danke ich Herrn Dr. A. Schulz und Herrn W. Fremut für die Überlassung von Untersuchungsdaten. Weiter danke ich den Mitarbeitern der Instituts für Bienenkunde, ohne deren Einsatz die Durchführung der praktischen Arbeit nicht möglich gewesen wäre.

\section{RÉSUME \\ DIAGNOSTIC QUANTITATIF DE L'INFESTATION DE RUCHES PAR VARROA JACOBSONI OUD. \\ ET DISTRIBUTION DE L'ACARIEN PARASITE AU SEIN DES RUCHES}

Une méthode fiable est nécessaire pour déterminer le taux d'infestation des colonies d'abeilles par $V$. jacobsoni. Elle sera utile pour lutter efficacement contre le parasite, pour développer de nouvelles méthodes de lutte et pour étudier la dynamique des populations de cet acarien. On a étudié la fiabilité de 2 méthodes simples : l'estimation du nombre total de Varroa 1) d'après le nombre d'acariens trouvés dans des échantillons d'abeilles que l'on a secouées dans de l'eau additionnée de détergent et 2) d'après des échantillons de cellules de couvain d'ouvrières lavés à la main.

On a divisé les ruches en échantillons selon les rayons (Tabl. 1). Les estimations d'acariens dans les ruches ont donc été basées sur 466 échantillons d'abeilles, avec une moyenne d'environ 1000 abeilles par échantillon, et sur 372 échantillons de couvain d'ouvrières, d'environ 500 cellules chacun. Ces estimations ont été comparées avec les nombres réels des acariens présents dans les ruches, déterminés soit par secouage de toutes les abeilles et lavage de toutes les cellules de couvain (46 ruches), soit par traitement acaricide (Folbex VA Neu, 49 ruches).

\section{1) Estimation de l'infestation}

Il existe une corrélation significative entre le nombre d'acariens présents dans les échantillons et 1'infestation des ruches $(r=0,62 ; p<0,001)$, mais la variabilité est élevée. La meilleure adéquation entre les valeurs estimées et l'infestation réelle a été obtenue avec la formule suivante : «nombre d'acariens dans la ruche $=($ Varroa par échantillon/abeilles par échantillon $) \times$ nombre de cadres $\times 22500 »$ (Fig. 2). De même on a trouvé une corrélation significative entre l'infestation de la ruche et le nombre d'acariens dans les échantillons de cellules de couvain $(r=0,57 ; p<0,001)$. La meilleure adéquation entre l'infestation de la ruche et l'infestation estimée a été obtenue avec la formule : "Nombre d'acariens $=$ (Varroa par échantillon/cellules de couvain par échantillon) $\times$ nombre de cadres $\times 7500$ (Fig. 4).

La fiabilité de l'estimation se caractérise par un intervalle de confiance de $95 \%$. Pour les estimations basées sur les échantillons de couvain, l'intervalle de confiance s'étend de 158 à 6300 acariens. L'estimation basée sur les échantillons d'abeilles est nettement plus fiable, mais l'intervalle de confiance s'étend encore de 263 à 3802 acariens (Tabl. 3). Il est possible d'accroître encore la fiabilité en combinant un échantillon d'abeilles et un échantilion de couvain ou, en plus, en 
considérant le nombre d'abeilles et le nombre de cellules de couvain dans les ruches. Néanmoins, même avec ces méthodes laborieuses, les estimations dévient fréquemment de plus de 2 fois ou de plus de la moitié de la valeur réelle. La fiabilité reste donc insuffisante et dépasse peu la fiabilité, également insuffisante, des diagnostics par chute naturelle des acariens morts au cours de l'été (Liebig, 1984).

\section{2) Causes des déviations}

Plus de la moitié des déviations de l'infestation estimée d'une ruche par rapport aux nombres réels d'acariens peut être attribuée aux différences parmi les ruches. Avec les deux méthodes décrites - échantillons d'abeilles et échantillons de cellules de couvain -, les estimations tendent à être trop basses lorsque la quantité de couvain est supérieure à la moyenne. Pourtant la prise en compte du nombre de cellules de couvain dans les calculs n'est pas susceptible d'accroître la précision de façon substantielle. Au-dessus d'un minimum d'environ 500 cellules, on peut s'attendre à trouver la moitié des acariens présents dans les cellules de couvain; ce chiffre augmente peu avec l'accroissement du nombre de cellules de couvain et présente des différences surprenantes d'une ruche à l'autre.

Les différences entre échantillons d'une même ruche participent, presqu'autant que les différences entre ruches, à la variation des estimations. Dans les échantillons d'abeilles, l'infestation est un peu plus élevée au centre de la ruche, particulièrement sur les rayons à couvain. Ces différences sont pourtant bien trop faibles pour rendre compte de la variance intra-ruche des échantillons d'abeilles. Dans les échantillons de couvain, les taux d'infestation varient largement d'un rayon de couvain à l'autre, et d'une région à l'autre d'un même rayon, pour des larves ayant à peu près le même âge. Cela est l'indication de fortes variations dans le temps du nombre d'acariens prêts à pénétrer dans les cellules, puisque les différences sont en particulier plus grandes que celles atttendues si un nombre variable de cellules de couvain était disponible pour un nombre constant d'acariens.

\section{SUMMARY}

\section{QUANTITATIVE DIAGNOSIS OF THE INFESTATION OF BEE HIVES BY VARROA JACOBSONI OUD. AND DISTRIBUTION OF THE PARASITIC MITE WITHIN THE HIVES}

A reliable method is needed to determine the rate of infestation of bee hives by $V$. jacobsoni. This would be useful in effective pest control, in the developement of new control methods and in the study of the population dynamics of this mite. The reliability of two simple methods was investigated : the estimation of the total numbers of $V$. jacobsoni by the numbers of mites found in bee samples shaken in detergent water and by samples of worker brood cells flushed by hand.

Hives were subdivided into samples according on the combs (Table 1). Estimates of mites in the hives were thus based on 466 bee samples with an average of approximately 1000 bees per sample and of 372 worker cell samples each containing approximately 500 cells. These estimates were compared with the actual numbers of mites in the hives determined either by shaking all bees and flushing all brood cells (46 hives) or by treatment with an acaricide (Folbex VA neu, 49 hives).

\section{1) Estimates of infestation}

The numbers of mites in the bee samples were significantly correlated with the infestation of the hives $(\mathrm{r}=0.62, \mathrm{p}<0.001)$, but the variability was considerable. The closest agreement between estimated values and actual hive infestation was obtained using the formula number of mites in the hive $=($ Varroa in sample $/$ bees in sample $) \times$ number of hive stories $\times 22500$ (Fig. 2). 
Similarly, a significant correlation between infestation of the hive and numbers of mites in the brood cell samples $(\mathrm{r}=0.57, \mathrm{p}<0.001)$ could be shown. The closest fit between hive infestation and estimated infestation was obtained by the formula Number of mites $=$ (Varroa in sample/brood cells in sample) $\times$ number of hive stories $\times 7500$ (Fig. 4).

The reliability of the sample estimates can be characterized by the $95 \%$ confidence interval. For estimates based on brood samples, the confidence interval ranged from 158 to 6300 mites based on an assumed infestation of 1000 mites. The estimate based on bee samples is clearly more reliable, but still the confidence interval ranged from 263 to 3802 mites (Table 3). A further increase of reliability is possible by combining a brood sample and a bee sample or, in addition, considering the numbers of bees and the numbers of brood cells in the hives. However, even with these laborious methods estimates will frequently deviate by more than twofold or half of the actual value. The reliability thus remains insufficient for many purposes and does not substantially exceed the also insufficient reliability of diagnoses by the natural fall of dead mites during summer (LIEBIG, 1984).

\section{2) Causes of deviations}

More than half of the deviations of the estimated hive infestation from the actual numbers of mites can be attributed to differences among the hives. With both methods - bee samples and brood cell samples - estimates tended to be too low when more than an average number of brood cells were present. However, including the numbers of brood cells in the calculations is not expected to increase the accuracy of prediction substantially. Above a minimum of approximately 500 cells about half of the mites can be expected to be in the brood cells with only a slight increase towards higher numbers of brood cells and surprising differences among hives.

Differences among samples from the same hive contributed to the variation of the estimates by almost the same degree as differences among hives. Only a small portion of this can be attributed to chance deviations of the numbers of mites in the samples. In bee samples, infestation was somewhat higher in the central area of the hives, particularly on the brood combs. However, these differences were far too small to account for the within-hive variance of the bee samples. In brood samples, infestation rates differed largely among brood combs as well as among areas of the same combs where larvae were of approximately the same age. This indicates strong fluctuations in time of the numbers of mites ready to enter cells, particularly since differences were greater than those expected if different numbers of brood cells are available to constant numbers of mites.

\section{BIBLIOGRAPHIE}

De Jong D., De Andrea Roma D., Goncalves L.S., 1982. - A Comparative Analysis of Shaking Solutions for the Detection of Varroa jacobsoni on Adult Honeybees. Apidologie, 13 (3), 297-306.

Fremuth W., 1984. - Populationsdynamik von Varroa jacobsoni OUD. 1904 in standardisierten Bienenvölkern von Apis mellifera L. im Beobachtungszeitraum Juni-Oktober 1983. Diplomarbeit an der Landesanstalt für Bienenkunde der Universität Hohenheim.

HÄNEL H., 1983. - Effect of $\mathrm{JH}_{\mathrm{III}}$ on the reproduction of Varroa jacobsoni. Apidologie, 14 (2), $137-142$.

HÄNEL H., 1985. - Das Juvenilhormon der Honigbiene als ein Auslöser für die Reproduktion des Parasiten Varroa jacobsoni OUD. unter Berücksichtigung der Morphologie des Reproduktionssystems der Milbe. Dissertation am Fachbereich Biologie der Johann-Wolfgang-Goethe Universität Frankfurt/Main. 
KraUs B., 1985. - Die Verteilung von Varroa jacobsoni OUD. 1904 auf Bienen verschiedener Altersstufen. Diplomarbeit am Fachbereich Biologie der Johann-Wolfgang-Goethe, Universität Frankfurt/Main.

Ljebig G., Schlipf U., Fremut W., Ludwig W., 1984. - Ergebnisse der Untersuchungen über die Befallsentwicklung der Varroa-Milbe in Stuttgart-Hohenheim 1983. Allg. dtsch. Imkerztg., 6, 185-190.

Maul V., 1984. - Empfehlungen zu Vorsorgemaßnahmen gegen Varroaschäden im Sommer 1984. I. Beurteilung der Befallsstärken und des Schadensrisikos nach dem Ergebnis der Herbstbehandlung 1983. Die Biene, 6, 249-253.

Ritter W., Perschil E., vom Hövell R., 1983. - Erkennen der Varroatose mit einfachen Untersuchungsmethoden. Allg. dtsch. Imkerztg., 7, 221-222.

Ritter W., Ruttner F., 1980. - Diagnoseverfahren. Allg. disch. Imkerztg., 5, 134-138.

Schulz A., 1984. - Reproduktion und Populationsentwicklung der parasitischen Milbe Varroa jacobsoni OUD. in Abhängigkeit vom Brutzyklus ihres Wirts Apis mellifera L. Dissertation am Fachbereich Biologie der Johann-Wolfgang-Goethe, Universität Frankfurt/Main. 